\title{
Effects of stand age and soil organic matter quality on soil bacterial and fungal community composition in Larix gmelinii plantations, Northeast China
}

\author{
li jianwei ${ }^{1}$, Sun Xiaoqian ${ }^{1}$, Li Ming ${ }^{1}$, Zou Jiying ${ }^{2}$, and Bian Hongfeng ${ }^{1}$ \\ ${ }^{1}$ Northeast Normal University \\ ${ }^{2}$ Jilin Institute of Chemical Technology
}

January 8, 2022

\begin{abstract}
It is of great interest to elucidate the biogeographic patterns of soil microorganisms and their driving forces, which is fundamental to predicting alterations in microbial-mediated functions arising from environment changes. Although the vertical movement of dissolved organic matter (DOM) drives the cycle of nutrients such as soil carbon but, in the restored ecosystem, the relationship between DOM and soil microbial nutrient utilization remains to be determined. Here, we investigated the changes of soil microbial community at 0-40 cm depth profile in three stages (10-, 30-, 50-years) of succession in Larix olgensis plantations and the fluorescence spectrum composition of DOM. With the increase of soil depth, the signal source of microorganisms increases. In a coniferous forest soil environment, the possible main source of DOM in deep soil is the production of microbial metabolism. Difficulty in the decomposition of organic matter determines the distribution and composition of microorganisms. Increasing forest age makes bacteria and fungi more specific and bacterial-fungal associations greater. Overall, our work contributes to the understanding of factors underlying microbial community distribution in plantation forests and the importance of DOM quality in building microbial communities.
\end{abstract}
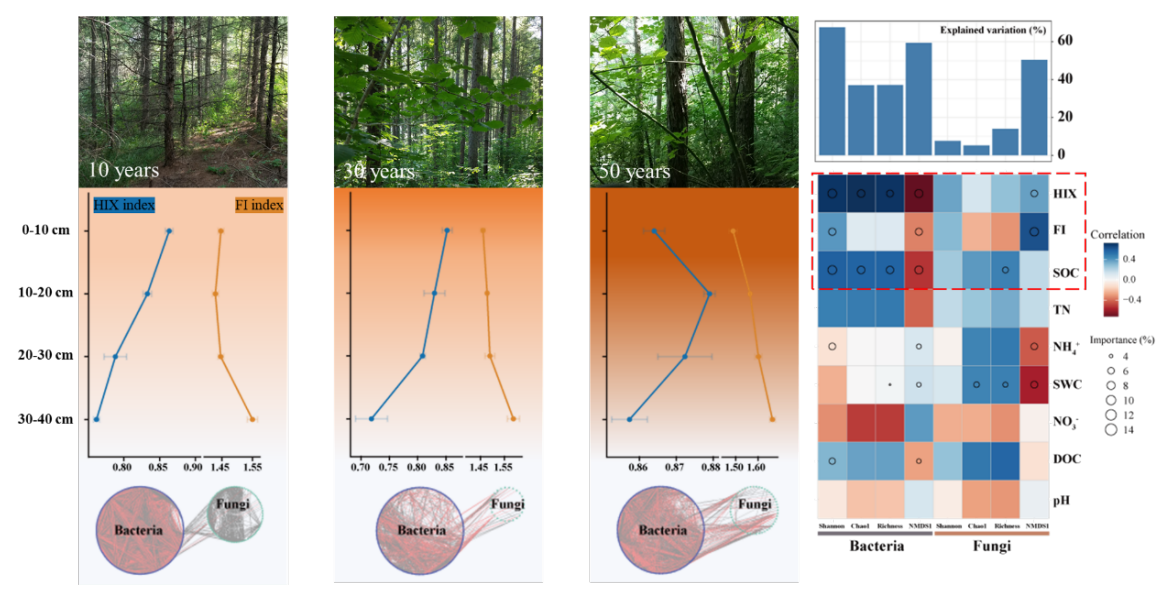

\section{Introduction}

Returning farmland to forest is an effective means to protect the ecological environment and prevent soil erosion; moreover, it effectively improves vegetation coverage, species diversity, and primary productivity 
(Wu et al., 2021). In Northeast China, afforestation account for $70 \%$ of the total forest area (Yang et al., 2010).Larix(L.) gmelinii has been widely used as a plantation species because of its rapid growth and excellent wood quality ( $\mathrm{Li}$ et al., 2020; Yu and Liu, 2020). The response of soil microbial communities to such returning farmland to forest little attention. It is of particular importance to understand the effects of such conversion on soil microbial community, which will further affect the maintenance of ecosystem services and functions.

Soil microorganisms fundamentally determine soil organic carbon (SOC) accumulation and renewal and affect soil carbon mineralization (Jiang et al., 2018; Maron et al., 2018). Soil active microbial communities play a central role in subsurface processes, especially in mediating soil organic decomposition and nutrient cycling in forest ecosystems (Jiao et al., 2018; Wagg et al., 2019). The interaction between forest SOC decomposition and soil microbial communities is key to understanding the feedback of terrestrial ecosystem processes to global climate change (Cavicchioli et al., 2019; Geisen et al., 2021; Zheng et al., 2019). The majority of soil microorganisms obtain carbon by decomposing different types of SOC, which have different decomposition abilities and mechanisms (Zhong et al., 2018).

In soil systems, the source and composition of dissolved organic matter (DOM) change with varying soil depth, and the source may change from plant to microbial with an increase in depth (Roth et al., 2019). DOM can combine with fine soil particles to form mineralized SOC; it can also stimulate soil microorganism activity and promote SOC decomposition (Gross and Harrison, 2019; Kleber et al., 2021). The vertical movement of DOM plays a crucial role in soil development, microbial metabolism, carbon and nutrient cycling, and distribution (Ye et al., 2020), and it drives the basic biogeochemical processes in forest soils (Kaiser and Kalbitz, 2012). DOM is an important carbon source for soil microorganisms. Solid organic macromolecules are decomposed into molecules with relatively small water solubility under the action of extracellular enzymes. Soluble substrates are a prerequisite for microbial diffusion through cell membranes (H. Liu et al., 2021; Roth et al., 2019). DOM is the most bioavailable organic matter in the soil, and its composition is highly dynamic and sensitive to environmental change (Fan et al., 2020). In addition, some studies have revealed that microorganisms are unable to utilize all carbon resources and exhibit a significant substrate preference (Huang et al., 2021).

Plantations play a vital role in supporting the timber industry, promoting local economic development, and mitigating global climate change (Tong et al., 2020; Zhu et al., 2017). With reduced logging and effective wildfire control, plantations are increasing in age and, thus, are storing more carbon. Most of the current studies on the change of soil carbon focus on the surface layer, that is, $0-20 \mathrm{~cm}$ depth (Cheng et al., 2017). However, the balance between soil carbon mineralization and decomposition in the sub-deep layer $(>20 \mathrm{~cm})$ may play an important role in the long-term carbon sequestration potential of SOC. Therefore, it is necessary to quantify the vertical change in soil carbon stability in plantations (Hou et al., 2019; Mayer et al., 2020; Yang et al., 2020). Returning farmland to forest can significantly change soil properties and nutrient status, and further soil microbial community (Liu et al., 2020). However, there are strong interactions between soil physico-chemical and biological properties. Thus, the combined analysis of all these factors during the returning farmland to forest can provide useful information for comprehensive evaluation the effects of plantations on soil quality and functions.

In this study, the diversity in the composition of soil dissolved organic carbon (DOC) in three different stands along with the soil layers $(0-40 \mathrm{~cm})$ and explored the relationships between DOM composition and bacterial and fungal communities (i.e., diversity, species composition, and microbial abundance) by absorption and fluorescence spectroscopy. The objectives of this study were (1) to determine the effects in three different stands along with the soil layers $(0-40 \mathrm{~cm})$ on soil chemical properties, (2) to compare and evaluate the influence of returning farmland to forest on soil microbial community, and (3) to determine whether DOM quality plays a predominant role in structuring the soil microbial community.

\section{Materials and methods}

\subsection{Site description and soil sampling}


The Jinchuan Forest Farm $\left(42^{\circ} 20^{\prime} \mathrm{N}, 126^{\circ} 24^{\prime} \mathrm{E}\right)$ in Huinan County, southwest of Changbai Mountain, is located in Northeast China (Fig. S1). The total area is $22.5 \mathrm{~km}^{2}$; the average altitude is $655 \mathrm{~m}$; the annual average temperature is $3.4{ }^{\circ} \mathrm{C}$, and the annual average precipitation is $1053.9 \mathrm{~mm}$. Soil samples were collected in July 2020. We selected three L. gmelinii plantations with different restoration years $(10,30$, and 50 years). Homogenous climatic conditions throughout the study site made it possible to compare and represent plantations with a different number of restoration years and the associated soil microbial communities.

Three sample plots $(30 \times 30 \mathrm{~m})$ were randomly selected at each study site. Soil samples were collected from five layers $(10,20,30$, and $40 \mathrm{~cm})$ along with the soil profile. The samples were screened to $2 \mathrm{~mm}$, stored at $4{ }^{\circ} \mathrm{C}$, and transported to the laboratory for immediate analyses. A total of 36 samples were collected $(3$ cultivation years of plantation $\times 3$ repeated samples $\times 4$ layer depths). Each sample was divided into three sub-samples, namely, (1) those air-dried at room temperature $\left(20{ }^{\circ} \mathrm{C}\right)$ for analyses of $\mathrm{pH}$, total nitrogen $(\mathrm{TN})$, soil water content (SWC), SOC and DOM; (2) those stored at $4{ }^{\circ} \mathrm{C}$ for analyses of soil ammonia nitrogen $\left(\mathrm{NH}_{4}{ }^{+}\right)$and nitrate nitrogen $\left(\mathrm{NO}_{3}{ }^{-}\right)$; and $(3)$ those stored at $-80{ }^{\circ} \mathrm{C}$ for analysis of eukaryotic and prokaryotic microorganisms.

\subsection{Soil physical, chemical, and microbial analyses}

Soil $\mathrm{pH}$ was determined with the slurry method: air-dried soil was shaken in water (soil: water $[\mathrm{m} / \mathrm{v}]=$ 1:2.5) for $2 \mathrm{~min}$, allowed to stand for $30 \mathrm{~min}$, and $\mathrm{pH}$ was measured in the supernatant with an electrode. For nitrate measurement, $10 \mathrm{~g}$ fresh soil was extracted into $50 \mathrm{~mL}$ of $2 \mathrm{M} \mathrm{KCl}$ (aq) with shaking for $1 \mathrm{~h}$ at $25 \operatorname{deg} \mathrm{C}$, followed by filtration; and, the filtrate was analyzed on a Continuous Flow Analyzer (Technicon Corporation, Oregon, U.S.A.). SOC content was determined by the wet oxidation method using potassium dichromate in acid medium followed by redox titration and TN using the Kjeldahl method.

The relative abundances of $\mathrm{C}$ compound classes were determined in air-dried soils using Fourier-transformed infrared spectroscopy (attenuated total reflection Fourier-transformed infrared spectroscopy), with 64 scans by a Thermo-Scientific (Waltham, MA, USA), Nicolet iS50 FT-IR and peak assignments were made following Parikh (Parikh et al., 2014; Qin et al., 2021). DOM extraction and fluorescence excitation-emission (EEM) analysis were conducted with reference to previous studies (Huang et al., 2020).

Briefly, $5 \mathrm{~g}$ of air-dried soil samples were placed in $50-\mathrm{mL}$ centrifuge tubes and mixed with $25 \mathrm{~mL}$ distilled water with a soil-to-water ratio of 1:2.5 (w/v). The mixture was then by a shaker at 25 at $200 \mathrm{rpm}$ for 12 hours in the dark. All of the extracts were centrifuged at 3000xg for $10 \mathrm{~min}$ and filtered through prewashed $0.45 \mu \mathrm{M}$ cellulose acetate filters. The concentration of DOM was determined by the TOC tester (Germany multi N/C 3100). Fluorescence EEM was measured with a Hitachi spectrophotometer (Hitachi, Tokyo, Japan) at ambient temperature, across the excitation wavelengths 220-550 nm with an interval of $5 \mathrm{~nm}$ and the emission wavelengths $250-550 \mathrm{~nm}$ with an interval of $5 \mathrm{~nm}$ and scanning speed at $3000 \mathrm{~nm} \mathrm{~min}^{-1}$. The filtered DOM samples were transferred into brown glass sample bottles to prevent photodecomposition and stored in a refrigerator at $4{ }^{\circ} \mathrm{C}$. All analyses were conducted within $24 \mathrm{~h}$ after extraction.

The humification index (HIX) describes the DOM humification degree, with a higher value corresponding to lower $\mathrm{H} / \mathrm{C}$ ratios and more ring structure. The HIX was determined using interpolated values for excitation at $254 \mathrm{~nm}$, as the area under the emission peak from 435 to $480 \mathrm{~nm}$ was divided by the area under the peak from 330 to $345 \mathrm{~nm}(\mathrm{Ohno}, 2002)$. The fluorescence index (FI), calculated as em $470 \mathrm{~nm} / \mathrm{em} 520 \mathrm{~nm}$ at ex $370 \mathrm{~nm}$, is an indicator of precursor material to the humic portion of OM, with higher values indicating microbe-dominated origins (FI [?] 1.8) and lower values indicating plant-dominated (FI [?] 1.2) (T. Liu et al., 2021; McKnight et al., 2001).

According to the instructions of the FastDNA SPIN Kit for Soil (Q-BIOgene, Carlsbad, USA), we extracted microbial DNA. And then, we detected the concentration and purity of DNA using an automatic microplate reader (BioTek ELX 800, USA). The primers 338F (5'-ACTCCTACGGGAGGCAGCA-3') and 806R (5'GGACTACHVGGGTWTCTAAT-3') (Mori et al., 2014) were used to amplify the V3-V4 hypervariable region of the bacterial 16S rRNA gene. The primers ITS1F (5'-CTTGGTCATTTAGAGGAAGTAA-3') and ITS2R (5'-GCTGCGTTCTTCATCGATGC-3') (Adams et al., 2013) were used to amplify the fungal ITS1 
region. The PCR amplification steps were as following: pre-denaturation at $94 \operatorname{deg} \mathrm{C}$ for $5 \mathrm{~min}$, followed by 30 cycles of deformation at $95 \operatorname{degC}$ for $30 \mathrm{~s}$, annealing at $58 \operatorname{degC}$ for $20 \mathrm{~s}$, elongation at $72 \operatorname{deg} \mathrm{C}$ for $6 \mathrm{~s}$, and a final extension at $72 \mathrm{degC}$ for $7 \mathrm{~min}$. The obtained PCR product was further purified and quantified using QuantiFluor-ST (Promega, USA) according to the manufacturer's procedure. Finally, all the gene sequencing was performed on an Illumina HiSeq PE150 system (Illumina Corporation, USA) by Biomarker Technologies Co, LTD.

Primer sequences were trimmed after the raw sequences were de-noised, sorted, and separated using Trimmomatic (version 0.33). The remaining sequences were filtered for redundancy, and all unique sequences for each sample were then clustered into operational taxonomic units (OTUs) at similarities of $97 \%$. Sequences with putative chimeras and ambiguous bases were discarded. The taxonomic identify (species level) of representative sequences for each OTU was determined using the Silva reference database (http://www.arb-silva.de) for the 16S rRNA genes and the Unite reference database (http://unite.ut.ee/index.php) for the ITS using the RDP naive Bayesian classifier with the BLAST tool in QIIME (http://qiime.org/index.html).

\subsection{Statistical analysis}

Two-way ANOVAs were used to analyze the effects of varied tree ages, soil depths, and their interaction on the soil properties and microbial alpha diversities (number of OTUs and Simpson's diversity and ShannonWiener indices). A Pearson correlation analysis assessed the association between microbial alpha diversity and environmental factors. A value of $p<0.05$ was considered significant. The heterogeneity of the variance was tested, and the original data were normalized by log-transformation or standardization prior to analysis when necessary. Using non-metric multidimensional scaling (NMDS), the dynamics of microbial community during the increase of L. gmelinii plantations age and then assessed through a permutational multivariate analysis of variance (PERMANOVA). The correlations between environmental parameters and microbial community profiles were then assessed through Redundancy analysis (RDA). A Mantel test was used to assess the correlations of microbial communities and environmental variables using the Vegan package. A partial Mantel test in the Vegan package was used to control the covarying effects of various factors. A classification random forest (RF) analysis was used to identify microbial taxa associated with stand age in L. gmeliniiplantations. The analysis aimed to test which microbial taxa are possible predictors of forest age change. Additionally, the functional profiles of soil prokaryotes and fungi were separately analyzed using FAPROTAX (Louca et al., 2016) and FUNGuild (Nguyen et al., 2016). To estimate species coexistence across different L. gmeliniiplantations, metacommunity co-occurrence networks consisting of all the members of the three microbial groups were constructed. To reduce rare OTUs in the dataset, we removed OTUs with a relative abundance $<0.5 \%$. Robust correlations with Spearman's correlation coefficients $(\rho)>0.7$ and false discovery rate-corrected p-values $<0.05$ were used to construct networks (Jiao et al., 2020; Shi et al., 2020). Then, the networks were constructed in $\mathrm{R}$ with the igraph package, and the related network indices were calculated. Finally, the networks were visualized in Gephi (version 0.9.3; https://gephi.org/). The node size was proportional to the number of connections (i.e., degrees), and the node color represented the microbial taxonomy. The link between each pair of nodes represented a positive (in green) or a negative (in red) correlation.

\section{Results}

\subsection{Changes of soil physical and chemical properties in an artificial forest with different recovery periods}

Soil properties including $\mathrm{pH}, \mathrm{NH}_{4}{ }^{+}$, and DOM quantity (represented by DOC concentration) and quality varied with respect to soil depth and recovery time increased. The soil was consistently acidic, with the lowest $\mathrm{pH}$ observed in the topsoil. 

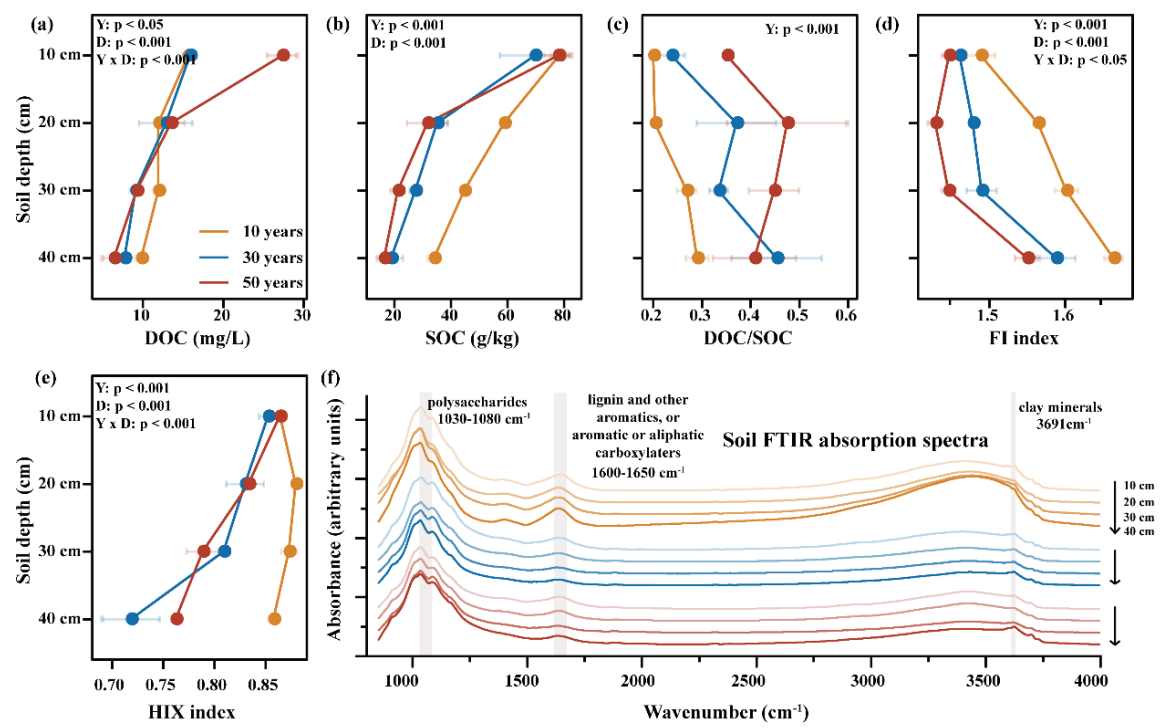

Fig. 1 soil properties: a-e; FT-IR: (f) fourier-transformed infrared spectra of soil organic matter mixtures (mixtures were prepared with replicate three samples). Mean values are shown with standard error $(\mathrm{n}=3)$. $\mathrm{Y}$ and D denote the effects of different ages and soil depth, respectively (only significant effects based on two-way ANOVA are shown)

There were some differences in the concentrations of DOM quantity and SOC in soil layers of the sampled stands along the L. gmeliniiafforestation along the chronosequence. SOC and TN content in the $0-10 \mathrm{~cm}$ soil layers was significantly higher than the $10-40 \mathrm{~cm}$ soil layers in each afforestation $(p<0.05$; Figs. 1a and 1c), and the SOC and TN content in the chronosequence were significantly different, mainly in the deep layer 10-40 cm. DOC/SOC ratio significantly increased with increasing forest age $(p<0.05)$. $\mathrm{NH}_{4}{ }^{+}$content ranged from 5.68 to 15.88 and increased with increasing forest age $(p<0.05)$ but did not affect the $\mathrm{NO}_{3}{ }^{-}$ contents $(p>0.05$; Table S1). The quality of DOM (FI and HIX index) in the soil changed with increasing forest age (Figs. 1d and 1e)). The FI index of different forest ages fluctuated around 1.5. FI index in subsoil significantly decreased over time, while in the topsoil, the change was not significant $(p>0.05)$. There were no significant differences in HIX index between soil layers in the younger stand (10 years old), but the HIX index was significantly higher in topsoil than in subsoil at the older stands (30 and 50 years old) $(p<0.05)$. In comparison with the results of previous studies (Gao et al., 2017), it can be inferred that the DOM of different forest ages may have similar sources in the L. gmelinii .

To investigate the structure of the soil organic matter, FT-IR spectroscopy was used to examine, whereas the spectra are generally similar between samples, the relative intensity of particular bands differs, revealing the SOC chemical changes during in afforestation (Hartman et al., 2017) (Fig. 1f). With increasing forest age polysaccharides $\left[1030-1080 \mathrm{~cm}^{-1}\right]$ weaken. 10 years plantations had more abundant polysaccharides, abundant lignins aromatics [1600-1650 $\left.\mathrm{cm}^{-1}\right]$, and less abundant clay minerals $\left[3691 \mathrm{~cm}^{-1}\right]$ than plantations aged 30 and 50 years. It indicated more cellulose (O-alkyl-C) plant material in the younger stand vs. more organic-mineral compounds in the older stands.

3.2 Soil Microbial community diversity, composition, and abundance of taxa covaried with different recovery periods and soil depth

A total of 1720 bacterial and 959 fungal operational taxonomic units (OTUs) were obtained, and each sample harbored 1343 bacterial and 238 fungal OTUs on average. The number of fungal OTUs is significantly lower than the bacterial OTUs. 

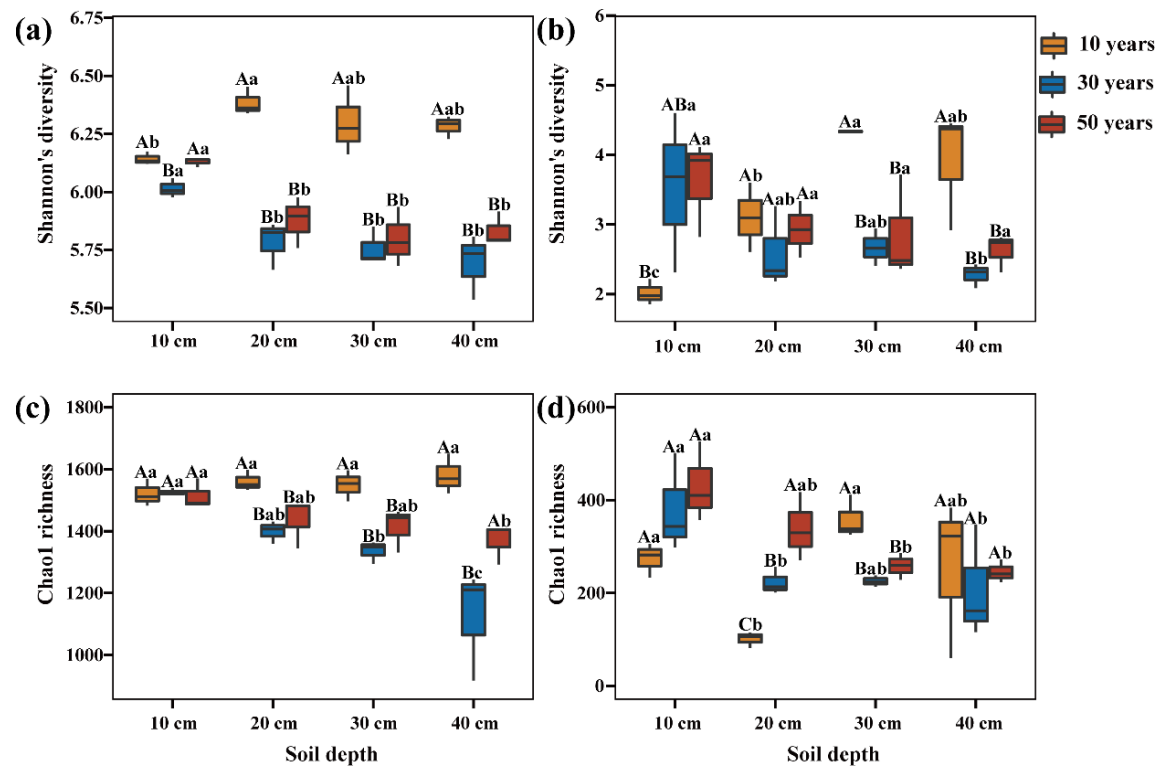

Fig. 2 Shannon diversity and Chao1 richness of bacterial (Figs. 2a and 2c) and fungal (Figs. 2b and 2d) communities in plantation stands of different ages. Different upper and lowercase letters indicate different levels among different ages and soil depth, respectively $(\mathrm{n}=3, p<0.05)$

The $\alpha$-diversity (represented by Shannon's diversity and Chao1 richness) of the soil bacteria community differed among 10-40 cm in 30 and 50 years plantations but not in $0-10 \mathrm{~cm}$ soil (Figs. 2a and 2c), and, the diversity measurements such as the Shannon index and Chao1 richness indicate that 0-10 cm has a higher $\alpha$-diversity than 10-40 cm. However, a major dissimilarity was observed among the fungal communities in the soil microhabitat samples collected from different stands (Figs. $2 \mathrm{~b}$ and $2 \mathrm{~d}$ ), indicating that the fungal communities were highly diverse in soil from different soil layers.
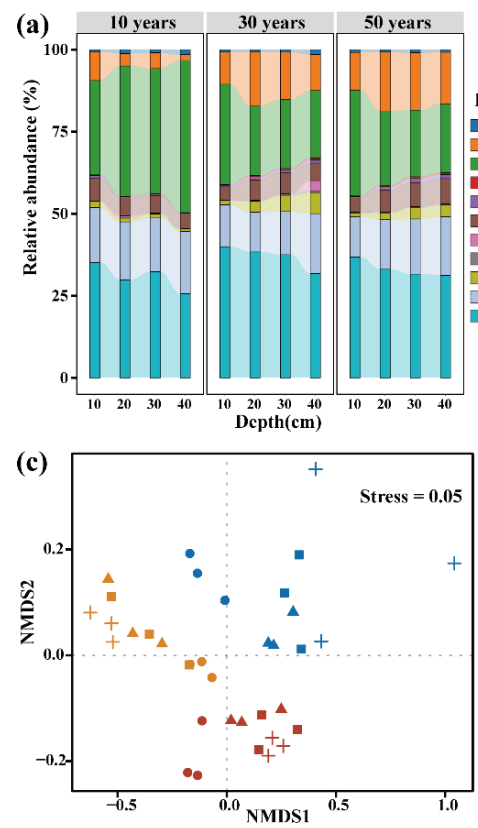

(b)

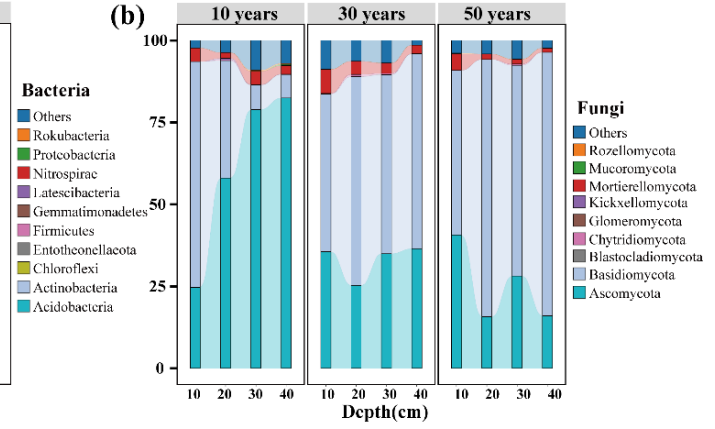

(d)

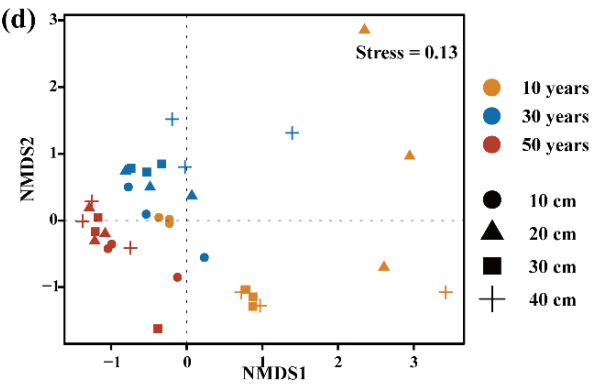


Fig. 3 (a)-(b): Compositions and structures of soil microbial communities between different stand ages in the L. gmeliniiplantations. The NMDS, the dynamics of microbial community during the increase of $L$. gmelinii plantations age and then assessed through a PERMANOVA.

The plot of NMDS (Figs. 3c and 3d) suggests variations in microbial beta diversity among the soil samples, with the response of soil bacterial beta diversity to afforestation time being larger than that of fungal beta diversity (bacteria, PERMANOVA, $\mathrm{r}=0.48, p<0.001$; fungal, PERMANOVA, $\mathrm{r}=0.31, p<0.001$ ), despite the significant variation in both species with afforestation time, and the differences in diversity between the restorative stages were much larger than the differences in diversity among soil depths.

Six bacterial phyla (Acidobacteria, Actinobacteria, Proteobacteria, Rokubacteria, Gemmatimonadetes, and Chloroflex) dominated forest soils, accounting for $95 \%$ of bacterial abundance. The relative abundances of these taxa varied by forest ages stages and soil depth. Notably, Rokubacteria significantly increased with increasing forest ages. Proteobacteria showed the opposite trend. Other phyla showed different responses with increasing stand age but these responses were insignificant. In the case of the fungal community, fungi could be classified into two different phyla, predominantly Ascomycota and Basidiomycota. The relative abundance of Basidiomycota increased but Ascomycota decreased with increasing forest age. The relative abundance of Basidiomycota gradually decreased with increasing soil depth in the younger stand (10 years old).

Using random-forest machine learning to discriminate samples with different samples based upon the microbiota composition (Zhang et al., 2018). The importance of indicator prokaryotic classes was assessed by 10-fold cross-validation (Xue et al., 2021). When the cross-validation error curve was at its lowest, a total of 24 OTUs were detected as biomarker fungi taxa and 42 OTUs as biomarker bacteria taxa. Among these classes, taxa exhibited different relative abundances in soils of different stand ages, and these results suggest that these taxa may be useful as biomarkers of soil microorganisms in planted forests (Fig. S2).

Using FUNGuild, 11 of all OTUs were assigned to putative fungal functional groups, which accounted for $54.5 \%$ of total biomarker fungi taxa. Pathotroph-saprotroph-symbiotroph (45.8\%) were the abundant functional groups across all samples (Fig. S2). For trophic modes, the relative abundances of some dominant taxonomic groups changed apparently with forest ages. The relative abundances of saprotroph and symbiotroph in 30 and 50 years forests were greater than those of 10 years forest group, while the relative abundance of pathotroph aerobic chemoheterotrophy (AC) and aromatic compound degradation (ACD) was significantly lower than that of 10 years forest. Relative abundance of aerobic nitrite oxidation (ANO) significantly increased with stand age. These changes are closely related to soil nutrient limitation.
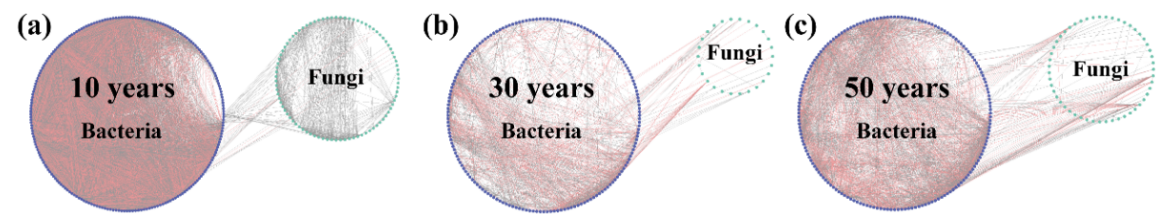

Fig. 4 Network of co-occurring bacteria and fungi OTUs across three different stand ages in the L. gmelinii plantations.

Table 1 Properties of soil bacteria and fungi co-occurrence networks

\begin{tabular}{llll}
\hline & OTUs (Number of network nodes) & OTUs (Number of network nodes) & Connections (Number of network e \\
\hline Community & Bacteria & Fungi & Bac-Bac \\
10 years & 216 & 87 & 8866 \\
30 years & 172 & 26 & 1127 \\
50 years & 172 & 51 & 2088 \\
\hline
\end{tabular}


Network complexity varied considerably across the three forest ages types (Table 1). The number of network edges (the number of bacterial and fungal connections) increased with increasing stand age (Fig. 4). The network complexity varied greatly among the three stand ages. The 30 years old microbial community had lower network complexity, fewer edges (1211), lower mean (12.23), and lower graph density (0.062) compared to the 10 and 50 years forest soils. 10 years forest soils had the most complex network with a higher number of nodes and edges and higher graph density.

\subsection{Microbial community diversity and composition of taxa covaried with soil properties}
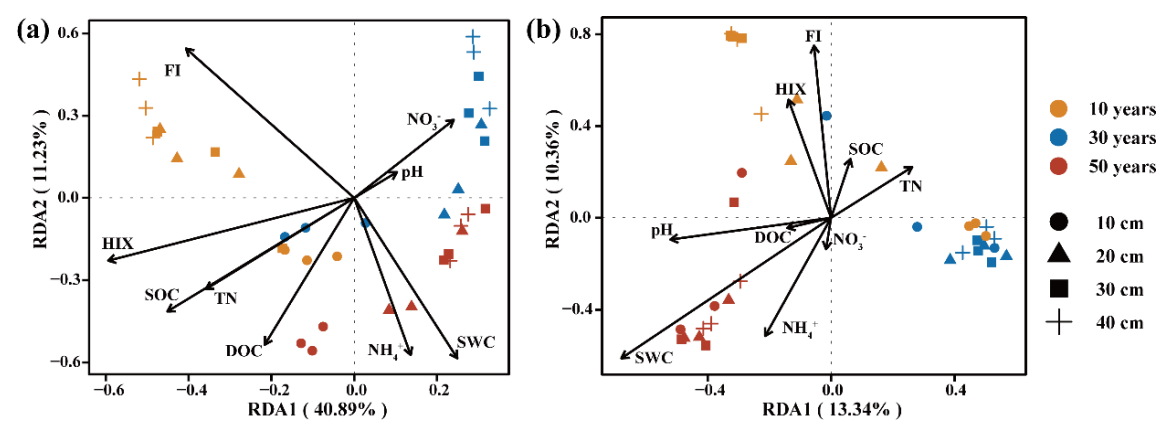

Fig. 5 Redundancy analyses (RDA) using pooling data of bacterial (a) and fungal (b) community and abiotic variables (arrows). The values of Axes 1 and 2 are percentages that the corresponding axis can explain.

Redundancy analysis (RDA) and Monte Carlo permutation test were used to provide a statistical analysis of the microbial community response to changes in different forest ages $(p<0.01)$ (Fig. 5). According to the RDA results the first two axes explained $52.12 \%$ of the total variation in the soil bacterial community (RDA1, $40.89 \%$; RDA2, 11.23\%), and HIX, FI, SOC, and SWC were the main factors influencing the structure of the soil bacterial community. The structure of bacteria was significantly correlated with soil FI index $(p<$ $0.01)$ in 10 years plantations, but was more strongly associated with $\mathrm{NO}_{3}{ }^{-}$and $\mathrm{FI}$ index $(p<0.05)$ in 30 years plantations, then SWC and $\mathrm{NH}_{4}{ }^{+}(p<0.01)$ had the greatest effect on bacterial community structure in 50 years plantations.

Differences in fungal community composition were mainly determined by SWC $(p<0.01)$, HIX $(p<0.01)$, and FI $(p<0.05)$, with HIX and FI indexes influencing the distribution of fungal communities in 10 years plantations and SWC and $\mathrm{NH}_{4}{ }^{+}(p<0.01)$ having a greater impact on fungal diversity in 50 years plantations. The first two axes explained $23.7 \%$ of the total variation in the soil fungal community (RDA1, $13.34 \%$; RDA2, 10.36\%).

Table 2 Mantel tests and partial Mantel tests showing the relationships between dissimilarities of microbial community composition and individual environmental variables after controlling the potential effect of age stand. Mantel statistic $\mathrm{r}$ and associated $p$ were determined by partial Mantel tests based on Spearman's correlation with 9999 permutations

\begin{tabular}{lll}
\hline Edaphic variables & Bacterial composition & Fungi composition \\
\hline Years & $0.48^{* * *}$ & $0.58^{* * *}$ \\
Deep & $0.21^{* * *}$ & 0.01 \\
Year x Deep & $0.55^{* * *}$ & $0.52^{* * *}$ \\
pH & -0.16 & -0.05 \\
SWC & -0.36 & 0.07 \\
DOC & -0.08 & -0.19 \\
SOC & $0.11^{*}$ & -0.25 \\
TN & -0.01 & -0.26
\end{tabular}




\begin{tabular}{lll}
\hline Edaphic variables & Bacterial composition & Fungi composition \\
\hline $\mathrm{NO}_{3}{ }^{-}$ & 0.03 & -0.12 \\
$\mathrm{NH}_{4}{ }^{+}$ & 0.08 & 0.08 \\
$\mathrm{FI}$ & $0.17^{* *}$ & $0.14^{*}$ \\
$\mathrm{HIX}$ & $0.23^{* *}$ & -0.08 \\
\hline
\end{tabular}

Significance levels: ***: $p<0.001 ; * *: p<0.01 ; *: p<0.05$.

Since forest age and soil depth also contributed to building microbial community composition, partial Mantel tests were performed to estimate the independent contribution of each environmental factor after removing the effects of forest age and soil depth. Partial Mantel test results showed that FI $(\mathrm{r}=0.11, p<0.01)$ and HIX $(\mathrm{r}=0.23, p<0.01)$ were environmental factors significantly associated with bacterial community composition (Table 2) and soil SOC $(\mathrm{r}=0.11, p<0.05)$ but their effects were apparently much smaller; FI was the key to influence the distribution of fungal communities $(\mathrm{r}=0.14, p<0.05)$ and other environmental factors were not significantly influenced.

Linear regression analyses showed that the diversity of bacteria and fungi all increased significantly as DOM quantity increased. Diversity of fungi all declined as FI increased ( $\mathrm{r}=0.32, p=0.058$; Fig. S3e) and bacteria increased as HIX increased $(\mathrm{r}=0.71, p<0.05$; Fig. S3c). This indicated that fungal communities were more diverse when DOM was more plant-dominated in origin than those microbial sources dominated and increasing humification of DOM significantly enhanced bacteria diversity.

\section{Discussion}

\subsection{Influence of recovery period on SOC stability of larch plantations}

This study shows that the recovery time of larch trees affects the microorganisms in the soil, and soil properties and microbial communities change with increasing stand age, with bacteria and fungi responding differently to increase in age with the stand. There is a very strong link between soil microbial communities and soil properties in plantations. The DOM quality of the soil, especially the source of DOM and the level of humification, strongly influenced the structural and functional diversity of bacteria and fungi.

Changes in soil microbial diversity ware controlled by the quality of soil carbon in silvicultural ecosystems, and resource use by soil microorganisms was largely dependent on the availability of organic matter, and previous studies had shown a strong relationship between soil carbon content and microbial community diversity (Shen et al., 2019).

The variation in soil microbial community diversity among different pine stand ages varied between soil depths, which may be due to differences in the quantity and quality of soil organic matter. Overall, the HIX index decreased with the increase of soil depth, which indicated that the increase of forest age DOM was more humified in the surface soil and the accumulated humus was gradually transformed by microbial decomposition with soil depth. In contrast, a large amount of newly generated organic matter was buried in the deep soil environment of the 10 years forest due to the influence of anthropogenic activities and the input of organic fertilizers and crop straw (Kramer and Gleixner, 2008). Along with this perennial plant residue lingering on the soil surface, which may increase anaerobic microsites and affect soil moisture and temperature and thus the decomposition of plant residues (Ramírez et al., 2020a), making a higher proportion of lignin and aromatic compounds in the surface soil, when the SOC is more difficult to be decomposed (Li et al., 2021). As restoration time and soil depth increased, humification in the soil would decrease, carbon from plants will increase, and organic matter in the soil will be more difficult to decompose.

\subsection{Effects of soil depth and plantation restoration period on microbial community structure}

The microbial community structure changed at different stand ages, and the microbial diversity was higher in the surface soils, with different community structures and species composition at different soil depths. 
Vertical gradients in microbial community structure have been reported in other soil environments that are associated with differences in soil properties with depth (Du et al., 2021; Sun et al., 2020).

Microorganisms promote the decomposition of soil humus and accelerate the turnover rate of soil organic matter, therefor afforestation leads to changes in soil microbial diversity and also affects the soil carbon content in afforested ecosystems (Chen et al., 2021; Kang et al., 2018). Significant differences in the microbial communities were found in the different sampling sites in NMDS plots.

Changes in bacterial diversity were only expressed in the deeper soils, probably due to the richer nutrient content and composition of the topsoil, which can support a more diverse microbial community. The relative abundance of Acidobateria in the soil was significantly higher in the later stages of afforestation restoration (50 years) compared to the early stages of restoration (10 years). Acidobateria was thought to be able to use soil polysaccharides (especially microbially synthesized polysaccharides) to supply its production, and organic matter in the soil is more present in the form of microbially synthesized carbon as the stand age increases (Shao et al., 2019). Proteobacteria showed a gradual decreased in relative abundance with increasing recovery time, and this was closely related to the organic matter availability content (DOC/SOC). Changes in the composition and availability of soil organic matter determine the role of these taxa.

In general, fungi exhibited slower biomass turnover rates but higher decomposition efficiency than bacteria in early silviculture, and as the age of the forest increases, the structure and amount of organic matter in the deep soil changes and humification decreases the diversity of fungi (Bastida et al., 2021; Heijboer et al., 2018). It was reported that in the acidic soil fungi represented by Ascomycota and Basidiomycota are the main decomposers (Shi et al., 2021; Zhou et al., 2017). Basidiomycota played an important role in degrading lignin (Zhang et al., 2020), and the relative abundance of Basidiomycota is higher in plantation forests with younger stand ages (in 10 years old soil environments) due to the high cellulose content and aromatic compounds in the topsoil. While in the deep soil layer due to the new carbon generated by the disturbance of early anthropogenic activities was transferred and buried deeper in the soil (Lorenz and Lal, 2005), the lignin content in the soil was low relative to the surface soil, and Basidiomycota phylum would be gradually replaced by Ascomycota (S-strategist) (Ho et al., 2017; Li et al., 2021).

The transfer and decomposition of soil organic matter should be carried out from top to bottom, and the organic matter of the substratum of the short-term vegetation restoration was still dominated by the organic matter imported under human disturbance.

With increasing afforestation age, litter input from old vegetation would be terminated and replaced by litter from new vegetation, while the soil $\mathrm{C}$ derived from the former litter would be decomposed and mineralized by soil microbes (Ramírez et al., 2020b), the content of easily available ammoniacal nitrogen in the soil increased and the content of soil nutrients increased (Hoffland et al., 2020). Organic matter breakdown results from a combination of physical fragmentation and the activities of microorganisms (bacteria and fungi).

Bacterial community structure was linked to the function of the bacterial community, the function of degradation of aromatic compounds was increased with increasing afforestation age, and the relative abundance of functional flora associated with nitrogen cycling was also increased. In contrast, the bacterial community of chemical heterotrophs needs to consume a large number of organic molecules in the soil as a source of energy (Ma et al., 2020), and the composition of organic matter in the soil environment of the 10 years afforestation forest was significantly more complex than that of the 30 and 50 years ones, so the relative abundance of chemical heterotrophic bacteria was higher in the 10 years forest. For fungi, the relative abundance of Saprotroph and Symbiotroph increased with the age of the stand. Fungi decomposing organic matter in the soil to obtain nutrients, and nitrogen in the soil which is mainly produced by the decomposition of organic matter by symbiotic fungi (Wang et al., 2021). Increasing forest age makes fungi simple and efficient, and humification of organic matter may be particularly important in the functions performed by fungi in these ecosystems.

In a coniferous forest soil environment, the early apoplastic material was not easy to be decomposed, result in the high content of aromatic and cellulose in the soil to be high (Jílková et al., 2019). As the age of the forest 
increased, the substances in the soil that were difficult to be decomposed gradually decreased, and the role played by microorganisms changes from poor to eutrophic, and in the soil difficulty in the decomposition of organic matter determines the distribution and composition of microorganisms (Amarasinghe et al., 2021).

In this study, the association of bacteria and fungi increased with increasing forest age, the bacterial-fungal diversity network became simple and specialized, the products to be metabolized and decomposed in the soil decreased with increasing forest age, difficulty to decompose substances such as lignin increased, and the multiplicity of network relationships gradually increased with the singularity of nutrient substrates (Jiang et al., 2021; Zheng et al., 2021). Increasing the age of the trees did not increase the complexity of the microbial network, and those different ages possessed different microbiota, indicating that microbes were highly selected by apoplastic properties and reflecting that increasing stand age makes microbial decomposition of apoplastic material more specialized and efficient. Although only speculative (Freilich et al., 2018), increasing forest age makes bacteria and fungi more specific and bacterial-fungal associations greater.

Afforestation/reforestation was recognized as an important approach for agricultural land restoration (Austin et al., 2020). While previous studies had mainly provided analyses of soil microbial community abundance and diversity in forests of different ages, the use of network analysis to assess soil microbial differences due to stand age can provide new insights into the potential mechanisms between recovery time and microbes during vegetation restoration.

\section{Conclusions}

In our study, the diversity and abundance of the soil microbial community increased continually during vegetation restoration. With time, vegetation restoration led to a significantly altered soil microbial community structure. Dissolved organic matter content and structure are related to standing age, and its changes (degree of humification, organic matter composition) are key drivers of changes in microbial community composition, and that organic matter decomposition in larch forest environments is likely to occur top-down, and that the interactions between bacterial and fungal relationships increase with increasing vegetation recovery time. The study provided a deeper understanding of the vertical movement of dissolved organic matter and microbial interactions in the process of vegetation restoration.

\section{Acknowledgements}

Data accessibility: Data share can be contacted with Prof. Bian (E-mail: bianhf108@nenu.edu.cn).

Funding : This study was jointly supported by the projects of the National Natural Science Foundation of China (41630749)

Availability of data and material : The data that support the findings of this study are available from the corresponding author upon reasonable request.

Conflicts of interest/Competing interests : The authors declare that they have no known competing financial interests or personal relationships that could have appeared to influence the work reported in this paper.

\section{Appendix A. Supplementary data}

Table S1. Basic physical and chemical properties of soil

Fig. S1 Soil sampling sites across the Jinchuan Forest Farm ( $\left.42^{\circ} 20^{\prime} \mathrm{N}, 126^{\circ} 24^{\prime} \mathrm{E}\right)$ in Huinan County, southwest of Changbai Mountain in China

Fig. S2 Microbial biomarkers and predicted functional profiles of microbes under different stand ages in the L. gmeliniiplantations. Top 24 fungal OTUs and 42 bacterial OTUs were identified using random-forest classification of the relative abundance of all OTUs. Heatmap of the relative abundance of biomarker families in the individual samples. Differences in biomarker functions in the FUNGuild and FAPROTAX database under different stand ages. Sap: Saprotroph; Sym: Symbiotroph; Pat: Pathotroph; ACD: aromatic compound 
degradation; ANO: aerobic nitrite oxidation; AAO: aerobic ammonia oxidation; Nit: nitrification; SR: sulfate respiration; AC: aerobic chemoheterotrophy

Fig. S3 Relationships between DOC, FI, HIX, and microbial diversity based on linear regression analysis. r and associated $\mathrm{P}$ values in each model are shown on the figure. (a), (b), (c): Bacteria richness. (d), (e), (f): Fungi richness.

\section{References}

Adams, R.I., Miletto, M., Taylor, J.W., Bruns, T.D., 2013. Dispersal in microbes: fungi in indoor air are dominated by outdoor air and show dispersal limitation at short distances. ISME J. 7, 1262-1273. https://doi.org/10.1038/ismej.2013.28

Amarasinghe, A., Knox, O.G.G., Fyfe, C., Lobry de Bruyn, L.A., Wilson, B.R., 2021. Response of soil microbial functionality and soil properties to environmental plantings across a chronosequence in south eastern Australia. Appl. Soil Ecol. 168, 104100. https://doi.org/10.1016/j.apsoil.2021.104100

Austin, K.G., Baker, J.S., Sohngen, B.L., Wade, C.M., Daigneault, A., Ohrel, S.B., Ragnauth, S., Bean, A., 2020. The economic costs of planting, preserving, and managing the world's forests to mitigate climate change. Nat. Commun. 11, 5946. https://doi.org/10.1038/s41467-020-19578-z

Bastida, F., Eldridge, D.J., García, C., Kenny Png, G., Bardgett, R.D., Delgado-Baquerizo, M., 2021. Soil microbial diversity-biomass relationships are driven by soil carbon content across global biomes. ISME J. 15, 2081-2091. https://doi.org/10.1038/s41396-021-00906-0

Cavicchioli, R., Ripple, W.J., Timmis, K.N., Azam, F., Bakken, L.R., Baylis, M., Behrenfeld, M.J., Boetius, A., Boyd, P.W., Classen, A.T., Crowther, T.W., Danovaro, R., Foreman, C.M., Huisman, J., Hutchins, D.A., Jansson, J.K., Karl, D.M., Koskella, B., Mark Welch, D.B., Martiny, J.B.H., Moran, M.A., Orphan, V.J., Reay, D.S., Remais, J.V., Rich, V.I., Singh, B.K., Stein, L.Y., Stewart, F.J., Sullivan, M.B., van Oppen, M.J.H., Weaver, S.C., Webb, E.A., Webster, N.S., 2019. Scientists' warning to humanity: microorganisms and climate change. Nat. Rev. Microbiol. 17, 569-586. https://doi.org/10.1038/s41579-019-0222-5

Chen, L., Xiang, W., Ouyang, S., Wu, H., Xia, Q., Ma, J., Zeng, Y., Lei, P., Xiao, W., Li, S., Kuzyakov, Y., 2021. Tight coupling of fungal community composition with soil quality in a Chinese fir plantation chronosequence. Land Degrad. Dev. 32, 1164-1178. https://doi.org/10.1002/ldr.3771

Cheng, L., Zhang, N., Yuan, M., Xiao, J., Qin, Y., Deng, Y., Tu, Q., Xue, K., Van Nostrand, J.D., Wu, L., He, Z., Zhou, X., Leigh, M.B., Konstantinidis, K.T., Schuur, E.A., Luo, Y., Tiedje, J.M., Zhou, J., 2017. Warming enhances old organic carbon decomposition through altering functional microbial communities. ISME J. 11, 1825-1835. https://doi.org/10.1038/ismej.2017.48

Du, X., Deng, Y., Li, S., Escalas, A., Feng, K., He, Q., Wang, Z., Wu, Y., Wang, D., Peng, X., Wang, S., 2021. Steeper spatial scaling patterns of subsoil microbiota are shaped by deterministic assembly process. Mol. Ecol. 30, 1072-1085. https://doi.org/10.1111/mec.15777

Fan, Y., Zhong, X., Lin, T.-C., Lyu, M., Wang, M., Hu, W., Yang, Z., Chen, G., Guo, J., Yang, Y., 2020. Effects of nitrogen addition on DOM-induced soil priming effects in a subtropical plantation forest and a natural forest. Biol. Fertil. Soils 56, 205-216. https://doi.org/10.1007/s00374-019-01416-0

Freilich, M.A., Wieters, E., Broitman, B.R., Marquet, P.A., Navarrete, S.A., 2018. Species co-occurrence networks: Can they reveal trophic and non-trophic interactions in ecological communities? Ecology 99, 690699. https://doi.org/10.1002/ecy.2142

Gao, J., Liang, C., Shen, G., Lv, J., Wu, H., 2017. Spectral characteristics of dissolved organic matter in various agricultural soils throughout China. Chemosphere 176, 108-116. https://doi.org/10.1016/j.chemosphere.2017.02.104 
Geisen, S., Hu, S., dela Cruz, T.E.E., Veen, G.F. (Ciska), 2021. Protists as catalyzers of microbial litter breakdown and carbon cycling at different temperature regimes. ISME J. 15, 618-621. https://doi.org/10.1038/s41396-020-00792-y

Gross, C.D., Harrison, R.B., 2019. The Case for Digging Deeper: Soil Organic Carbon Storage, Dynamics, and Controls in Our Changing World. Soil Syst. 3, 28. https://doi.org/10.3390/soilsystems3020028

Hartman, W.H., Ye, R., Horwath, W.R., Tringe, S.G., 2017. A genomic perspective on stoichiometric regulation of soil carbon cycling. ISME J. 11, 2652-2665. https://doi.org/10.1038/ismej.2017.115

Heijboer, A., de Ruiter, P.C., Bodelier, P.L.E., Kowalchuk, G.A., 2018. Modulation of Litter Decomposition by the Soil Microbial Food Web Under Influence of Land Use Change. Front. Microbiol. 9, 2860. https://doi.org/10.3389/fmicb.2018.02860

Ho, A., Di Lonardo, D.P., Bodelier, P.L.E., 2017. Revisiting life strategy concepts in environmental microbial ecology. FEMS Microbiol. Ecol. 93. https://doi.org/10.1093/femsec/fix006

Hoffland, E., Kuyper, T.W., Comans, R.N.J., Creamer, R.E., 2020. Eco-functionality of organic matter in soils. Plant Soil 455, 1-22. https://doi.org/10.1007/s11104-020-04651-9

Hou, Y., Chen, Y., Chen, X., He, K., Zhu, B., 2019. Changes in soil organic matter stability with depth in two alpine ecosystems on the Tibetan Plateau. Geoderma 351, 153-162. https://doi.org/10.1016/j.geoderma.2019.05.034

Huang, M., Chai, L., Jiang, D., Zhang, M., Jia, W., Huang, Y., 2021. Spatial Patterns of Soil Fungal Communities Are Driven by Dissolved Organic Matter (DOM) Quality in Semi-Arid Regions. Microb. Ecol. 82, 202-214. https://doi.org/10.1007/s00248-020-01509-6

Huang, M., Chai, L., Jiang, D., Zhang, M., Jia, W., Huang, Y., 2020. Spatial Patterns of Soil Fungal Communities Are Driven by Dissolved Organic Matter (DOM) Quality in Semi-Arid Regions. Microb. Ecol. https://doi.org/10.1007/s00248-020-01509-6

Jiang, S., Xing, Y., Liu, G., Hu, C., Wang, X., Yan, G., Wang, Q., 2021. Changes in soil bacterial and fungal community composition and functional groups during the succession of boreal forests. Soil Biol. Biochem. 161, 108393. https://doi.org/10.1016/j.soilbio.2021.108393

Jiang, Y., Zhou, H., Chen, L., Yuan, Y., Fang, H., Luan, L., Chen, Y., Wang, X., Liu, M., Li, H., Peng, X., Sun, B., 2018. Nematodes and Microorganisms Interactively Stimulate Soil Organic Carbon Turnover in the Macroaggregates. Front. Microbiol. 9. https://doi.org/10.3389/fmicb.2018.02803

Jiao, S., Chen, W., Wang, J., Du, N., Li, Q., Wei, G., 2018. Soil microbiomes with distinct assemblies through vertical soil profiles drive the cycling of multiple nutrients in reforested ecosystems. Microbiome 6 , 146. https://doi.org/10.1186/s40168-018-0526-0

Jiao, S., Yang, Y., Xu, Y., Zhang, J., Lu, Y., 2020. Balance between community assembly processes mediates species coexistence in agricultural soil microbiomes across eastern China. ISME J. 14, 202-216. https://doi.org/10.1038/s41396-019-0522-9

Jílková, V., Jandová, K., Sim, A., Thornton, B., Paterson, E., 2019. Soil organic matter decomposition and carbon sequestration in temperate coniferous forest soils affected by soluble and insoluble spruce needle fractions. Soil Biol. Biochem. 138, 107595. https://doi.org/10.1016/j.soilbio.2019.107595

Kaiser, K., Kalbitz, K., 2012. Cycling downwards - dissolved organic matter in soils. Soil Biol. Biochem. 52, 29-32. https://doi.org/10.1016/j.soilbio.2012.04.002

Kang, H., Gao, H., Yu, W., Yi, Y., Wang, Y., Ning, M., 2018. Changes in soil microbial community structure and function after afforestation depend on species and age: Case study in a subtropical alluvial island. Sci. Total Environ. 625, 1423-1432. https://doi.org/10.1016/j.scitotenv.2017.12.180 
Kleber, M., Bourg, I.C., Coward, E.K., Hansel, C.M., Myneni, S.C.B., Nunan, N., 2021. Dynamic interactions at the mineral-organic matter interface. Nat. Rev. Earth Environ. 2, 402-421. https://doi.org/10.1038/s43017-021-00162-y

Kramer, C., Gleixner, G., 2008. Soil organic matter in soil depth profiles: Distinct carbon preferences of microbial groups during carbon transformation. Soil Biol. Biochem. 40, 425-433. https://doi.org/10.1016/j.soilbio.2007.09.016

Li, D., Yu, S., Zeng, M., Liu, X., Yang, J., Li, C., 2020. Selection and Validation of Appropriate Reference Genes for Real-Time Quantitative PCR Analysis in Needles of Larix olgensis under Abiotic Stresses. Forests 11, 193. https://doi.org/10.3390/f11020193

Li, H., Yang, S., Semenov, M.V., Yao, F., Ye, J., Bu, R., Ma, R., Lin, J., Kurganova, I., Wang, X., Deng, Y., Kravchenko, I., Jiang, Y., Kuzyakov, Y., 2021. Temperature sensitivity of SOM decomposition is linked with a K-selected microbial community. Glob. Change Biol. 27, 2763-2779. https://doi.org/10.1111/gcb.15593

Liu, H., Xu, H., Wu, Y., Ai, Z., Zhang, J., Liu, G., Xue, S., 2021. Effects of natural vegetation restoration on dissolved organic matter (DOM) biodegradability and its temperature sensitivity. Water Res. 191, 116792. https://doi.org/10.1016/j.watres.2020.116792

Liu, T., Wang, X., Zhu, E., Liu, Z., Zhang, X., Guo, J., Liu, X., He, C., Hou, S., Fu, P., Shi, Q., Feng, X., 2021. Evolution of the Dissolved Organic Matter Composition along the Upper Mekong (Lancang) River. ACS Earth Space Chem. 5, 319-330. https://doi.org/10.1021/acsearthspacechem.0c00292

Liu, T., Wu, X., Li, H., Alharbi, H., Wang, J., Dang, P., Chen, X., Kuzyakov, Y., Yan, W., 2020. Soil organic matter, nitrogen and $\mathrm{pH}$ driven change in bacterial community following forest conversion. For. Ecol. Manag. 477, 118473. https://doi.org/10.1016/j.foreco.2020.118473

Liu, Y., Zhang, J., Yang, W., Wu, F., Xu, Z., Tan, B., Zhang, L., He, X., Guo, L., 2018. Canopy gaps accelerate soil organic carbon retention by soil microbial biomass in the organic horizon in a subalpine fir forest. Appl. Soil Ecol. 125, 169-176. https://doi.org/10.1016/j.apsoil.2018.01.002

Lorenz, K., Lal, R., 2005. The Depth Distribution of Soil Organic Carbon in Relation to Land Use and Management and the Potential of Carbon Sequestration in Subsoil Horizons, in: Advances in Agronomy. Academic Press, pp. 35-66. https://doi.org/10.1016/S0065-2113(05)88002-2

Louca, S., Parfrey, L.W., Doebeli, M., 2016. Decoupling function and taxonomy in the global ocean microbiome. Science 353, 1272-1277. https://doi.org/10.1126/science.aaf4507

Ma, J., Liu, H., Zhang, C., Ding, K., Chen, R., Liu, S., 2020. Joint response of chemistry and functional microbial community to oxygenation of the reductive confined aquifer. Sci. Total Environ. 720, 137587. https://doi.org/10.1016/j.scitotenv.2020.137587

Maron, P.-A., Sarr, A., Kaisermann, A., Leveque, J., Mathieu, O., Guigue, J., Karimi, B., Bernard, L., Dequiedt, S., Terrat, S., Chabbi, A., Ranjard, L., 2018. High Microbial Diversity Promotes Soil Ecosystem Functioning. Appl. Environ. Microbiol. 84. https://doi.org/10.1128/AEM.02738-17

Mayer, M., Prescott, C.E., Abaker, W.E.A., Augusto, L., Cecillon, L., Ferreira, G.W.D., James, J., Jandl, R., Katzensteiner, K., Laclau, J.-P., Laganiere, J., Nouvellon, Y., Pare, D., Stanturf, J.A., Vanguelova, E.I., Vesterdal, L., 2020. Tamm Review: Influence of forest management activities on soil organic carbon stocks: A knowledge synthesis. For. Ecol. Manag. 466, 118127. https://doi.org/10.1016/j.foreco.2020.118127

McKnight, D.M., Boyer, E.W., Westerhoff, P.K., Doran, P.T., Kulbe, T., Andersen, D.T., 2001. Spectrofluorometric characterization of dissolved organic matter for indication of precursor organic material and aromaticity. Limnol. Oceanogr. 46, 38-48. https://doi.org/10.4319/lo.2001.46.1.0038

Mori H., Maruyama F., Kato H., Toyoda A., Dozono A., Ohtsubo Y., Nagata Y., Fujiyama A., Tsuda M., Kurokawa K., 2014. Design and Experimental Application of a Novel Non-Degenerate Universal Primer Set 
that Amplifies Prokaryotic 16S rRNA Genes with a Low Possibility to Amplify Eukaryotic rRNA Genes. DNA Res. 21, 217-227. https://doi.org/10.1093/dnares/dst052

Nguyen, N.H., Song, Z., Bates, S.T., Branco, S., Tedersoo, L., Menke, J., Schilling, J.S., Kennedy, P.G., 2016. FUNGuild: An open annotation tool for parsing fungal community datasets by ecological guild. Fungal Ecol. 20, 241-248. https://doi.org/10.1016/j.funeco.2015.06.006

Ohno, T., 2002. Fluorescence Inner-Filtering Correction for Determining the Humification Index of Dissolved Organic Matter. Environ. Sci. Technol. 36, 742-746. https://doi.org/10.1021/es0155276

Parikh, S.J., Goyne, K.W., Margenot, A.J., Mukome, F.N.D., Calderon, F.J., 2014. Chapter One - Soil Chemical Insights Provided through Vibrational Spectroscopy, in: Sparks, D.L. (Ed.), Advances in Agronomy. Academic Press, pp. 1-148. https://doi.org/10.1016/B978-0-12-800132-5.00001-8

Qin, S., Kou, D., Mao, C., Chen, Y., Chen, L., Yang, Y., 2021. Temperature sensitivity of permafrost carbon release mediated by mineral and microbial properties. Sci. Adv. 7, eabe3596. https://doi.org/10.1126/sciadv.abe3596

Ramirez, P.B., Calderon, F.J., Fonte, S.J., Santibanez, F., Bonilla, C.A., 2020a. Spectral responses to labile organic carbon fractions as useful soil quality indicators across a climatic gradient. Ecol. Indic. 111, 106042. https://doi.org/10.1016/j.ecolind.2019.106042

Ramirez, P.B., Fuentes-Alburquenque, S., Diez, B., Vargas, I., Bonilla, C.A., 2020b. Soil microbial community responses to labile organic carbon fractions in relation to soil type and land use along a climate gradient. Soil Biol. Biochem. 141, 107692. https://doi.org/10.1016/j.soilbio.2019.107692

Roth, V.-N., Lange, M., Simon, C., Hertkorn, N., Bucher, S., Goodall, T., Griffiths, R.I., Mellado-Vazquez, P.G., Mommer, L., Oram, N.J., Weigelt, A., Dittmar, T., Gleixner, G., 2019. Persistence of dissolved organic matter explained by molecular changes during its passage through soil. Nat. Geosci. 12, 755-761. https://doi.org/10.1038/s41561-019-0417-4

Shao, P., Liang, C., Rubert-Nason, K., Li, X., Xie, H., Bao, X., 2019. Secondary successional forests undergo tightly-coupled changes in soil microbial community structure and soil organic matter. Soil Biol. Biochem. 128, 56-65. https://doi.org/10.1016/j.soilbio.2018.10.004

Shen, C., Wang, L., Li, M., 2016. The altitudinal variability and temporal instability of the climate-treering growth relationships for Changbai larch (Larix olgensis Henry) in the Changbai mountains area, Jilin, Northeastern China. Trees 30, 901-912. https://doi.org/10.1007/s00468-015-1330-0

Shen, F., Wu, J., Fan, H., Liu, W., Guo, X., Duan, H., Hu, L., Lei, X., Wei, X., 2019. Soil N/P and C/P ratio regulate the responses of soil microbial community composition and enzyme activities in a long-term nitrogen loaded Chinese fir forest. Plant Soil 436, 91-107. https://doi.org/10.1007/s11104-018-03912-y

Shi, X., Zhao, X., Ren, J., Dong, J., Zhang, H., Dong, Q., Jiang, C., Zhong, C., Zhou, Y., Yu, H., 2021. Influence of Peanut, Sorghum, and Soil Salinity on Microbial Community Composition in Interspecific Interaction Zone. Front. Microbiol. 12, 1306. https://doi.org/10.3389/fmicb.2021.678250

Shi, Y., Delgado-Baquerizo, M., Li, Y., Yang, Y., Zhu, Y.-G., Penuelas, J., Chu, H., 2020. Abundance of kinless hubs within soil microbial networks are associated with high functional potential in agricultural ecosystems. Environ. Int. 142, 105869. https://doi.org/10.1016/j.envint.2020.105869

Sun, T., Wang, Y., Hui, D., Jing, X., Feng, W., 2020. Soil properties rather than climate and ecosystem type control the vertical variations of soil organic carbon, microbial carbon, and microbial quotient. Soil Biol. Biochem. 148, 107905. https://doi.org/10.1016/j.soilbio.2020.107905

Tong, X., Brandt, M., Yue, Y., Ciais, P., Rudbeck Jepsen, M., Penuelas, J., Wigneron, J.-P., Xiao, X., Song, X.-P., Horion, S., Rasmussen, K., Saatchi, S., Fan, L., Wang, K., Zhang, B., Chen, Z., Wang, Y., 
Li, X., Fensholt, R., 2020. Forest management in southern China generates short term extensive carbon sequestration. Nat. Commun. 11, 129. https://doi.org/10.1038/s41467-019-13798-8

Wagg, C., Schlaeppi, K., Banerjee, S., Kuramae, E.E., van der Heijden, M.G.A., 2019. Fungalbacterial diversity and microbiome complexity predict ecosystem functioning. Nat. Commun. 10, 4841. https://doi.org/10.1038/s41467-019-12798-y

Wang, K., Bi, Y., Cao, Y., Peng, S., Christie, P., Ma, S., Zhang, J., Xie, L., 2021. Shifts in composition and function of soil fungal communities and edaphic properties during the reclamation chronosequence of an opencast coal mining dump. Sci. Total Environ. 767, 144465. https://doi.org/10.1016/j.scitotenv.2020.144465

Wu, Y., Chen, W., Entemake, W., Wang, J., Liu, H., Zhao, Z., Li, Y., Qiao, L., Yang, B., Liu, G., Xue, S., 2021. Long-term vegetation restoration promotes the stability of the soil micro-food web in the Loess Plateau in North-west China. CATENA 202, 105293. https://doi.org/10.1016/j.catena.2021.105293

Xue, D., Chen, H., Zhan, W., Huang, X., He, Y., Zhao, C., Zhu, D., Liu, J., 2021. How do water table drawdown, duration of drainage, and warming influence greenhouse gas emissions from drained peatlands of the Zoige Plateau? Land Degrad. Dev. 32, 3351-3364. https://doi.org/10.1002/ldr.4013

Yang K., Zhu J., Zhang M., Yan Q., Sun O.J., 2010. Soil microbial biomass carbon and nitrogen in forest ecosystems of Northeast China: a comparison between natural secondary forest and larch plantation. J. Plant Ecol. 3, 175-182. https://doi.org/10.1093/jpe/rtq022

Yang, M., Wang, S., Zhao, X., Gao, X., Liu, S., 2020. Soil properties of apple orchards on China's Loess Plateau. Sci. Total Environ. 723, 138041. https://doi.org/10.1016/j.scitotenv.2020.138041

Ye, Q., Wang, Y.-H., Zhang, Z.-T., Huang, W.-L., Li, L.-P., Li, J., Liu, J., Zheng, Y., Mo, J.-M., Zhang, W., Wang, J.-J., 2020. Dissolved organic matter characteristics in soils of tropical legume and non-legume tree plantations. Soil Biol. Biochem. 148, 107880. https://doi.org/10.1016/j.soilbio.2020.107880

Yu, J., Liu, Q., 2020. Larix olgensis growth-climate response between lower and upper elevation limits: an intensive study along the eastern slope of the Changbai Mountains, northeastern China. J. For. Res. 31, 231-244. https://doi.org/10.1007/s11676-018-0788-1

Zhang, J., Zhang, N., Liu, Y.-X., Zhang, X., Hu, B., Qin, Y., Xu, H., Wang, H., Guo, X., Qian, J., Wang, W., Zhang, P., Jin, T., Chu, C., Bai, Y., 2018. Root microbiota shift in rice correlates with resident time in the field and developmental stage. Sci. China Life Sci. 61, 613-621. https://doi.org/10.1007/s11427-018-9284-4

Zhang, S., Wang, Y., Sun, L., Qiu, C., Ding, Y., Gu, H., Wang, L., Wang, Z., Ding, Z., 2020. Organic mulching positively regulates the soil microbial communities and ecosystem functions in tea plantation. BMC Microbiol. 20, 103. https://doi.org/10.1186/s12866-020-01794-8

Zheng, H., Yang, T., Bao, Y., He, P., Yang, K., Mei, X., Wei, Z., Xu, Y., Shen, Q., Banerjee, S., 2021. Network analysis and subsequent culturing reveal keystone taxa involved in microbial litter decomposition dynamics. Soil Biol. Biochem. 157, 108230. https://doi.org/10.1016/j.soilbio.2021.108230

Zheng, Q., Hu, Y., Zhang, S., Noll, L., Bockle, T., Dietrich, M., Herbold, C.W., Eichorst, S.A., Woebken, D., Richter, A., Wanek, W., 2019. Soil multifunctionality is affected by the soil environment and by microbial community composition and diversity. Soil Biol. Biochem. 136, 107521. https://doi.org/10.1016/j.soilbio.2019.107521

Zhong, Y., Yan, W., Wang, R., Wang, W., Shangguan, Z., 2018. Decreased occurrence of carbon cycle functions in microbial communities along with long-term secondary succession. Soil Biol. Biochem. 123, 207-217. https://doi.org/10.1016/j.soilbio.2018.05.017

Zhou, J., Bai, X., Zhao, R., 2017. Microbial communities in the native habitats of Agaricus sinodeliciosus from Xinjiang Province revealed by amplicon sequencing. Sci. Rep. 7, 15719. https://doi.org/10.1038/s41598-017-16082-1 
Zhu, J., Zhou, X., Fang, W., Xiong, X., Zhu, B., Ji, C., Fang, J., 2017. Plant Debris and Its Contribution to Ecosystem Carbon Storage in Successional Larix gmelinii Forests in Northeastern China. Forests 8, 191. https://doi.org/10.3390/f8060191 